\title{
Oscillatory Shear Stress-Induced Arginase Activity May Explain Reduced Exhaled Nitric Oxide Levels after Vest Chest Physiotherapy in Cystic Fibrosis
}

\author{
Christoph Nowak \\ Division of Pulmonology, University Hospital Zurich, Raemistraße 100, 8091 Zurich, Switzerland \\ Correspondence should be addressed to Christoph Nowak; nowakchr@googlemail.com
}

Received 7 February 2014; Accepted 24 February 2014; Published 3 April 2014

Academic Editor: Charlie Strange

Copyright (c) 2014 Christoph Nowak. This is an open access article distributed under the Creative Commons Attribution License, which permits unrestricted use, distribution, and reproduction in any medium, provided the original work is properly cited.

The well-executed study by Sisson et al. [1] demonstrates the potential of vest chest physiotherapy (VCPT) in improving airway clearance in cystic fibrosis (CF) patients. The authors point out that they observed a nonsignificant tendency towards higher exhaled nitric oxide $\left(\mathrm{NO}_{x}\right)$ levels in CF compared to healthy control subjects which is at odds with previous findings of lower $\mathrm{NO}_{x}$ in $\mathrm{CF}[2,3]$. Contrary to Sisson et al.s hypothesis, VCPT in CF patients reduced rather than increased $\mathrm{NO}_{x}$. The authors discuss this unexpected finding with regard to increased cellular NO utilisation and distal airway mucous barriers to NO diffusion.

An alternative explanation involves NO synthetase (NOS) and arginase activity in airway epithelial cells. Both enzymes compete for L-arginine as substrate and imbalances in activity levels are believed to be important in the pathogenesis of airway inflammation and hyperreactivity [4]. Arginase converts L-arginine into L-ornithine and urea, effectively modulating NOS activity, proinflammatory oxidant species generation, and airway remodelling [5]. Impaired lung function in CF is likely associated with reduced $\mathrm{NO}$-mediated bronchodilation arising from low levels of L-arginine, impaired NOS expression, and increased arginase activity [6,7]. Elevated systemic arginase and concomitantly reduced L-arginine levels were observed in acutely hospitalised CF patients and normalised after successful treatment [8]. Increased arginase activity, in addition to limiting $\mathrm{NO}$ production, also contributes to CF lung pathology through downstream products [9], is associated with Pseudomonas infection, and inversely related to lung function [10]. Arginase is moreover thought to play a role in the pathogenesis of other lung diseases like asthma and chronic obstructive pulmonary diseases [11, 12]. Recently, inhaled L-arginine was demonstrated to be a safe and potentially beneficial treatment approach in CF [13].

A possible mechanism to explain Sisson et al.s [1] surprising finding of lower $\mathrm{NO}_{x}$ after VCPT may be an increase in arginase activity through oscillatory mechanical stimulation of lung epithelial cells. Several studies in animal and cell models have demonstrated that specific patterns of mechanical stimulation can induce vascular endothelial arginase expression and activity. For instance, oscillatory shear stress induced stronger arginase activation than application of unidirectional shear force in porcine [14] and ApoE-deficient murine carotid artery segments [15]. An in vitro study showed that cyclic stretching of vascular smooth muscle cells upregulated arginase mRNA expression and enzyme activity whilst inhibiting NOS [16]. The VCPT device used in Sisson et al.s [1] study produced oscillatory inflation/deflation cycles at a rate of $10-15 \mathrm{~Hz}$ throughout 20 -minute treatment sessions. Thus, a possible explanation for reduced exhaled NO could be oscillatory shear stress-induced upregulation of arginase activity and associated inhibition of NOS. Whilst the observed vascular endothelial response in arginase activity to shear forces remains to be demonstrated for airway epithelial cells, the suggested link provides a plausible theory to account for Sisson et al's intriguing findings. 


\section{Conflict of Interests}

The author declares that there is no conflict of interests regarding the publication of this paper.

\section{References}

[1] J. H. Sisson, T. A. Wyatt, J. A. Pavlik, P. S. Sarna, and P. J. Purphy, "Vest chest physiotherapy airway clearance is associated with nitric oxide metabolism," Pulmonary Medicine, vol. 2013, Article ID 291375, 6 pages, 2013.

[2] P. J. Barnes, R. A. Dweik, A. F. Gelb et al., "Exhaled nitric oxide in pulmonary diseases a comprehensive review," Chest, vol. 138, no. 3, pp. 682-692, 2010.

[3] M. Högman, "Extended NO analysis in health and disease," Journal of Breath Research, vol. 6, no. 4, Article ID 047103, 2010.

[4] A. Strapkova and M. Antosova, "Competition of NO synthases and arginase in the airways hyperreactivity," General Physiology and Biophysics, vol. 30, no. 1, pp. 75-83, 2011.

[5] R. C. Benson, K. A. Hardy, and C. R. Morris, "Arginase and arginine dysregulation in asthma," Journal of Allergy, vol. 2011, Article ID 736319, 12 pages, 2011.

[6] H. Grasemann and F. Ratjen, "Nitric oxide and 1-arginine deficiency in cystic fibrosis," Current Pharmaceutical Design, vol. 18, no. 5, pp. 726-736, 2012.

[7] H. Grasemann, R. Schwiertz, S. Matthiesen, K. Racké, and F. Ratjen, "Increased arginase activity in cystic fibrosis airways," The American Journal of Respiratory and Critical Care Medicine, vol. 172, no. 12, pp. 1523-1528, 2005.

[8] H. Grasemann, R. Schwiertz, C. Grasemann, U. Vester, K. Racké, and F. Ratjen, "Decreased systemic bioavailability of Larginine in patients with cystic fibrosis," Respiratory Research, vol. 7, article 87, 2006.

[9] H. Grasemann, D. Shehnaz, M. Enomoto, M. Leadley, J. Belik, and F. Ratjen, "L-ornithine derived polyamines in cystic fibrosis airways," PLoS ONE, vol. 7, no. 10, Article ID e46618, 2012.

[10] B. S. Murphy, H. M. Bush, V. Sundareshan et al., "Characterization of macrophage activation states in patients with cystic fibrosis," Journal of Cystic Fibrosis, vol. 9, no. 5, pp. 314-322, 2010.

[11] H. Maarsingh, T. Pera, and H. Meurs, "Arginase and pulmonary diseases," Naunyn-Schmiedeberg's Archives of Pharmacology, vol. 378, no. 2, pp. 171-184, 2008.

[12] J.-M. Tadié, P. Henno, I. Leroy et al., "Role of nitric oxide synthase/arginase balance in bronchial reactivity in patients with chronic obstructive pulmonary disease," The American Journal of Physiology: Lung Cellular and Molecular Physiology, vol. 294, no. 3, pp. L489-L497, 2008.

[13] H. Grasemann, E. Tullis, and F. Ratjen, "A randomized controlled trial on inhaled L-arginine in patients with cystic fibrosis," Journal of Cystic Fibrosis, vol. 12, no. 5, pp. 468-474, 2013.

[14] T. N. Thacher, V. Gambillara, F. Riche, P. Silacci, N. Stergiopulos, and R. F. da Silva, "Regulation of arginase pathway in response to wall shear stress," Atherosclerosis, vol. 210, no. 1, pp. 63-70, 2010.

[15] V. C. Olivon, R. A. Fraga-Silva, D. Segers et al., "Arginase inhibition prevents the low shear stress-induced development of vulnerable atherosclerotic plaques in ApoE-/- mice," Atherosclerosis, vol. 227, no. 2, pp. 236-243, 2013.

[16] W. Durante, L. Liao, S. V. Reyna, K. J. Peyton, and A. I. Schafer, "Physiological cyclic stretch directs L-arginine transport and metabolism to collagen synthesis in vascular smooth muscle," The FASEB Journal, vol. 14, no. 12, pp. 1775-1783, 2000. 


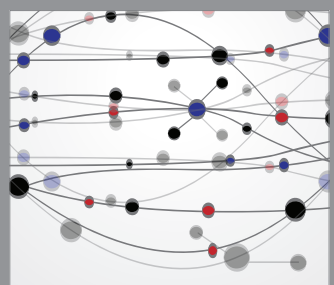

The Scientific World Journal
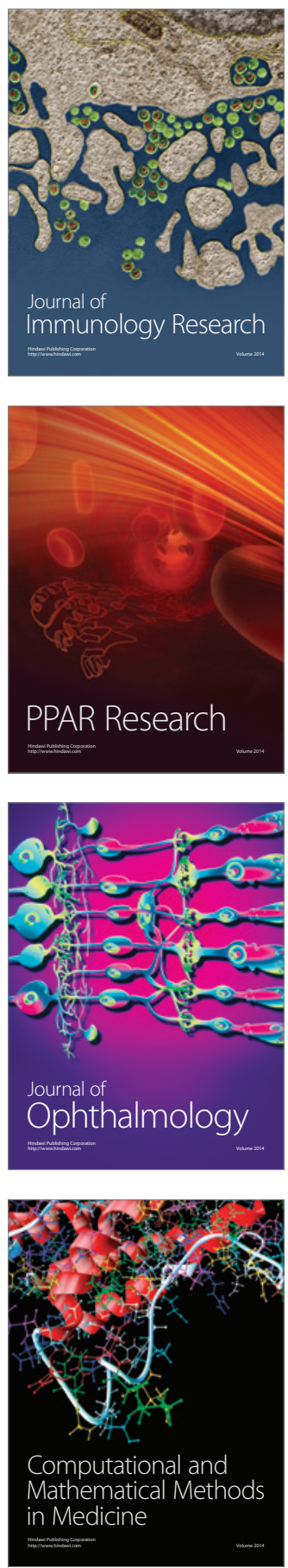

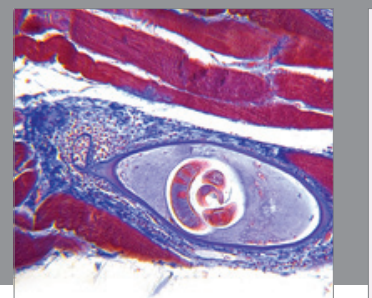

Gastroenterology

Research and Practice
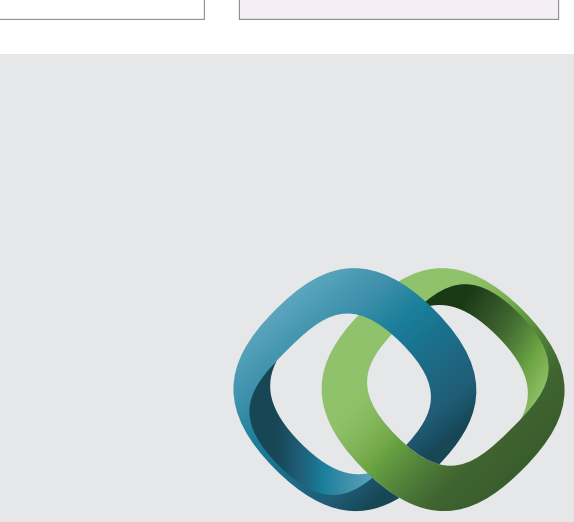

\section{Hindawi}

Submit your manuscripts at

http://www.hindawi.com
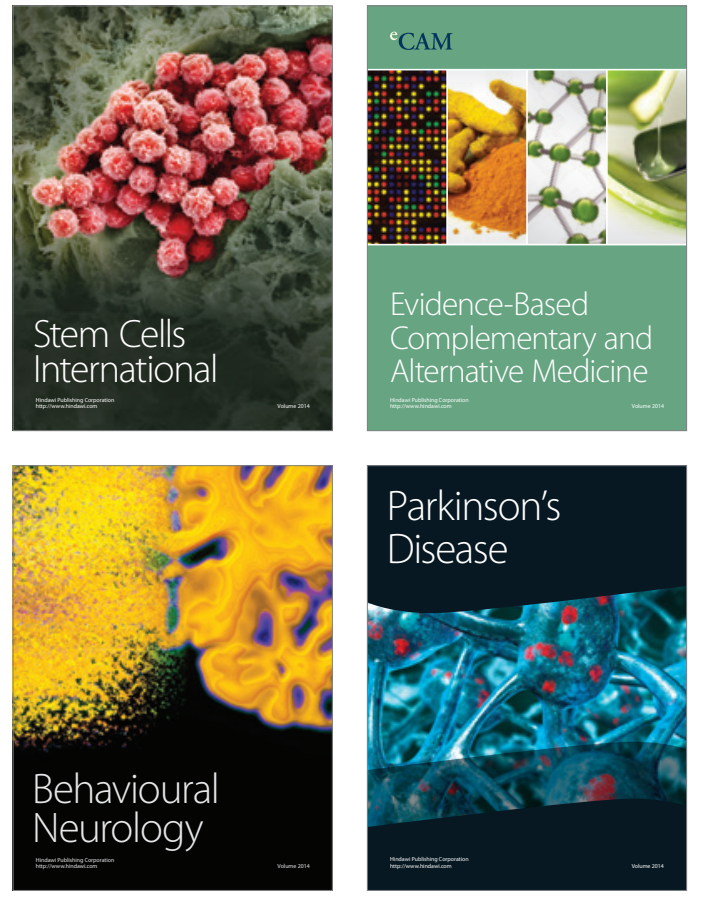
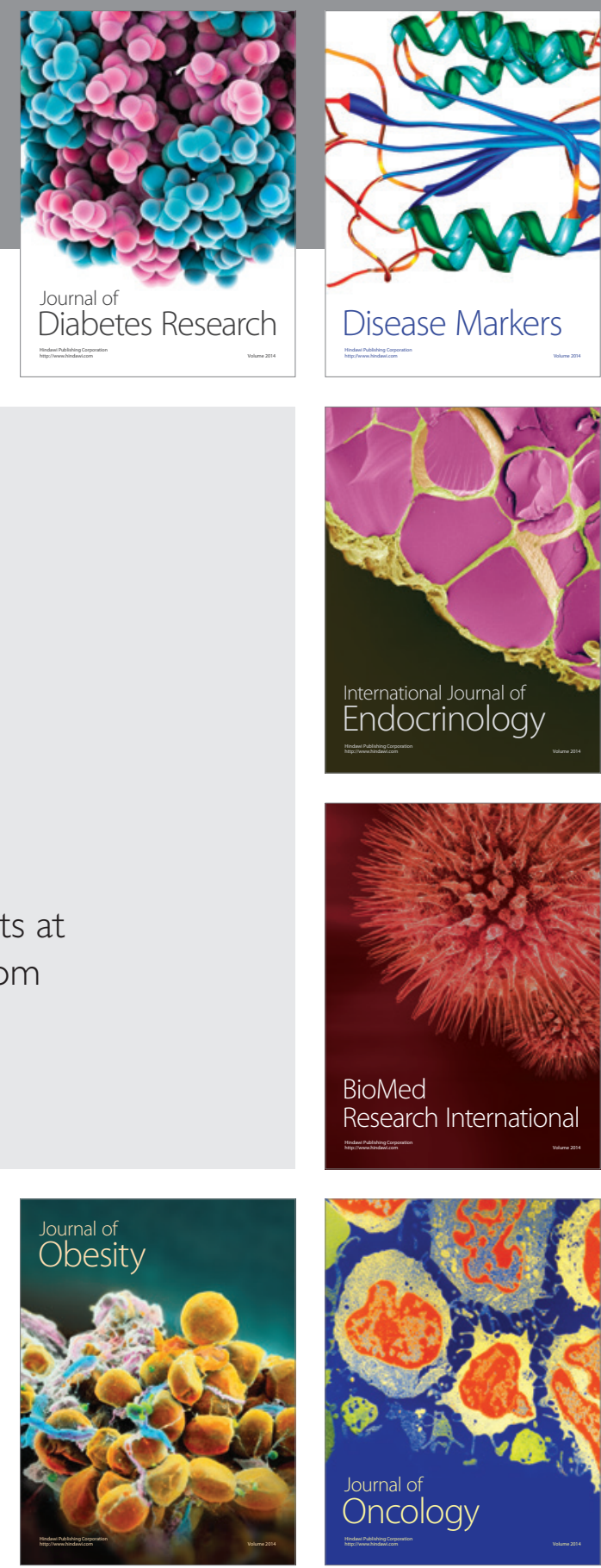

Disease Markers
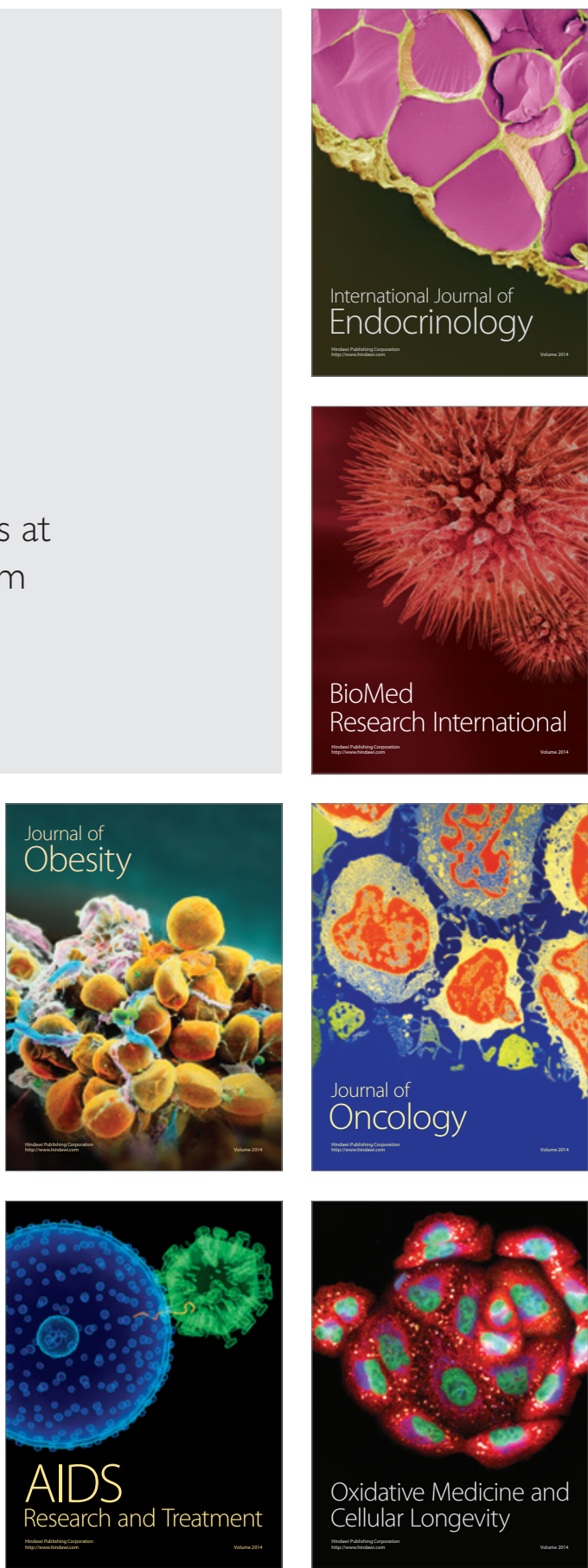